\title{
Study on Characteristics of Lightweight Aggregate Concrete Made From Foam and Ordinary Portland Cement
}

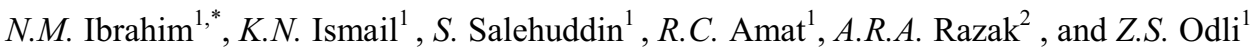 \\ ${ }^{1}$ School of Environmental Engineering, University Malaysia Perlis (UniMAP), Kompleks Pusat \\ Pengajian Jejawi3, 02600 Arau, Perlis, Malaysia. \\ ${ }^{2}$ School Electrical System Engineering, University Malaysia Perlis (UniMAP), Pauh Putra \\ Engineering Campus, 02600 Arau, Perlis, Malaysia.
}

\begin{abstract}
The production and characteristic of lightweight bubble aggregates (LBA) are presented in this paper. The LBA are produced by mixing between the foam and ordinary Portland cement according to the composition which has been set. Then, the characteristics of LBA such as density, water absorption, specific gravity, compressive strength, aggregate impact value and microscopic analysis of the LBA are analyzed. Those characteristics are identified in order to ensure that the LBA are successfully categorized into lightweight aggregate. The loose bulk density is obtained at $812.5 \mathrm{~kg} / \mathrm{m} 3$ which can be categorized under lightweight aggregate group. For water absorption the value obtained is $9.7 \%$ which is slightly higher compared to normal aggregate. Meanwhile the average specific gravity obtained for the samples of LBAis 1.75. Compressive strength for the aggregates was $\quad 17.76 \mathrm{MPa}$. The highest compressive strength for LBA foamed concrete was obtained at $25 \%$ replacement with $7.83 \mathrm{MPa}$. Thus, the LBA have a significant features and characteristics that can be used as coarse aggregates in concrete.
\end{abstract}

\section{Introduction}

Lightweight aggregate is one type of coarse aggregate that is normally used in the production of lightweight concrete elements such as concrete block, beams, and columns as well as in slabs for precast concrete. It is proven from previous research that have been done that there are many advantages infusing lightweight aggregate in concrete which are: a) total permanent action or also known as dead load can be reduced that may results in reduced footings sizes and significant reduction in total reinforcement, lighter and smaller precast elements which needs smaller and less expensive handling and transporting element, smaller sizes of columns and slab and beam dimensions, bigger space availability and better thermal insulation, enhanced fire resistance[1].

In lightweight concrete production, the most popular method is to use lightweight aggregate (LWA). It is now common in construction industry that the lightweight concrete

\footnotetext{
*Corresponding author: norlia@unimap.edu.my
} 
has been made using artificial lightweight aggregate for the coarse aggregate substitution and using normal weight sand for the fine aggregate. Examples of artificial lightweight aggregates such as expanded clay and shale are made because they are most suitable for the production of structural quality lightweight concrete. Commercially available, these types of lightweight aggregates are obtained through heat treatment which also known as sintering process temperature $1000-1200{ }^{\circ} \mathrm{C}$. Due to this high temperature process, overall production process will acquire higher fuel costs. As a result, overall construction cost will increase. Therefore, it is very beneficial to find a lightweight aggregate from a natural source. However, with the increasing use of these types of lightweight aggregates, it will consequently cause a severe depletion of the natural resources. As an alternative source for lightweight aggregate, artificial lightweight aggregate is used. These artificial aggregates as alternative building material will definitely provide a significant saving in the overall cost of construction and also preserve natural environment [2].

Other than using LWA, lightweight concrete can also be produced using foamed concrete which is either made from a cement paste or mortar. Foamed concrete is generally classified as lightweight concrete, where air-voids are entrapped in mortar by suitable foaming agent. It is noted that it possesses high flow ability, low self weight, minimal consumption of aggregate, controlled low strength and more importantly excellent thermal insulation properties. With proper control of dosage of foam, a wide range of densities $\left(1800-400 \mathrm{~kg} / \mathrm{m}^{3}\right)$ of foamed concrete can be obtained for application to structural, partition, insulation and filling grades[3].

With a wide range of applications, foamed concrete is an extremely versatile material. The properties of foamed concrete are very suitable to be used in many other applications besides for concrete production. Its application varies from road sub-bases, bridge abutments, and bridge strengthening up to road widening. It is very cost effective and especially advantageous when used for projects on soft ground. Its higher porosity effects will help to mitigate flood in urban area. To achieve a proper road structure; usually allows less excavation of the road bed, because cellular concrete will provide high strength and insulation in one layer [4].

\section{Materials and methods}

\subsection{Preparation of samples}

Ordinary Portland cement and foam are the main ingredients in producing LBA. Figure 1 shows the overall method in production of LBA. By using dilution factor of 1:2.5 where one portion of foaming agent diluted with two and half portion of water, nice and thick foam will be produced. The foam that has been produced was added into the Ordinary Portland Cement with the ratio of $1: 2$. The mixture will be stir thoroughly and carefully until all cement and foams are well blended. Then, the fresh paste will be formed into rounded shape lightweight aggregate. The mixture was based from the research made by[5]. Next, the LBA were placed in the oven at temperature of $105 \pm 5{ }^{\circ} \mathrm{C}$ for 24 hours. LBAs were leaved at room temperature to cools it down as shown in Figure 2. 


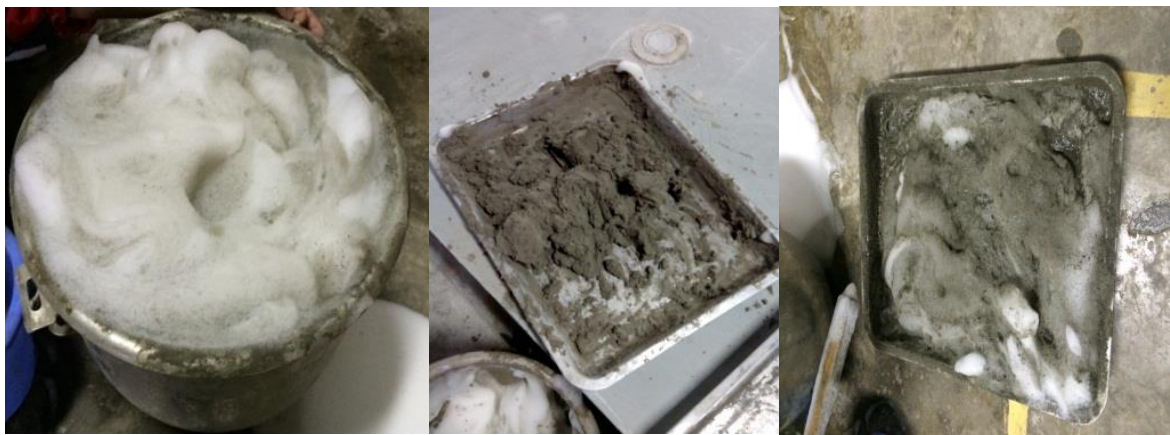

Fig. 1. The mixing process of LBA.

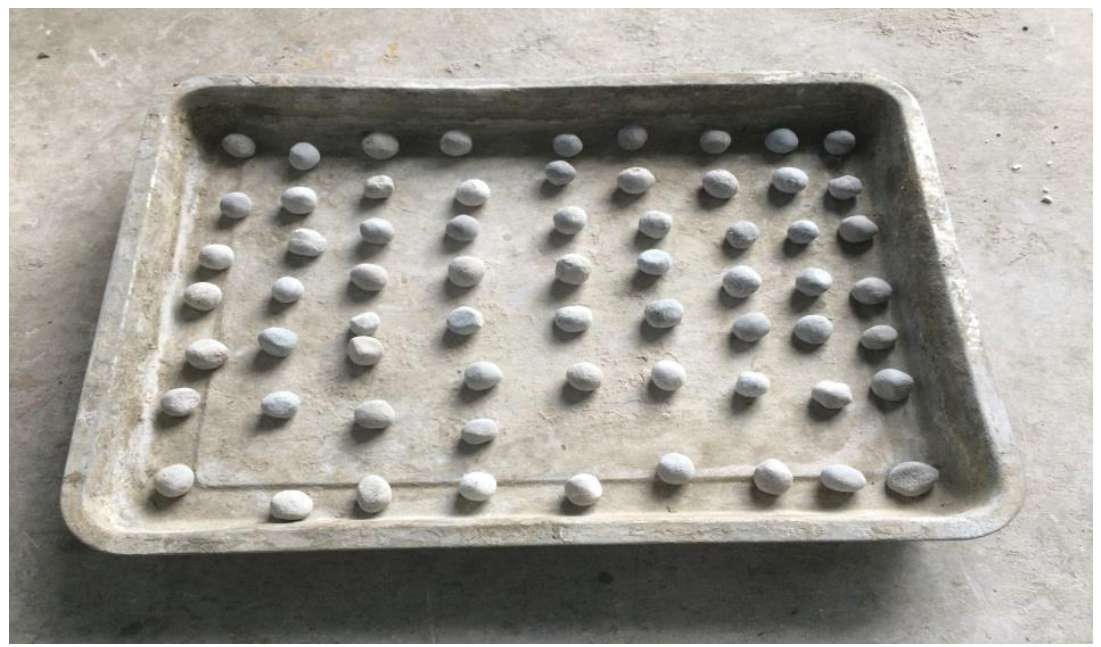

Fig. 2. LBA at room temperatures.

\subsection{Loose bulk density test}

In this study, loose bulk density was determined according to the standard of ASTM $\mathrm{C} 29 / \mathrm{C} 29 \mathrm{M}$ as the aggregate was below the maximum size, $37.5 \mathrm{~mm}$. the loose bulk density is the mass of non-compacted aggregates required to fill the container of a unit volume after aggregates were batched based on volume. Loose bulk density was determined by shovelling method [6].

\subsection{Water absorption test}

Water Absorption was the increase in mass of aggregate due to water penetration into the pores of the particles during a prescribed period of time, but not including water adhering to the outside surface of the particles. It is conducted to calculate the change in the mass of an aggregate due to water absorbed in the pore that present in the aggregate [7]. Referring to the method in ASTM C127, $2 \mathrm{~kg}$ of lightweight aggregate (LWA)are washed and dried before the test sample is placed in the oven at atemperature of $105 \pm 5{ }^{\circ} \mathrm{C}$ for $1-3$ hours. Next, let it cools down at room temperature until it can be handled. Then the samples were immersed in water at room temperature for a period of $24 \pm 4$ hours. The test sample was removed from the water and wiped until it's became saturated surface dry. Then the lightweight aggregate will be weighted and recorded as B. Afterwards, LWA is placed in 
the oven at temperature of $105 \pm 5{ }^{\circ} \mathrm{C}$ for $24 \pm 4$ hours and it is weighted and recorded as A. Water absorption can be calculated by knowing the difference in weight of LBA.

\subsection{Specific gravity test}

Specific gravity can be known as the ratio of the weight of a given volume of aggregate to the weight of an equal volume of water using an apparatus known as Densimeter. The result of specific gravity for LBA will be compared with granite.

\subsection{Aggregate impact value}

The aggregate impact value test is conducted to determine the strength value of coarse aggregate that is conducted by using apparatus name Aggregate Impact Value Tester. It follows the Indian Standard

\subsection{Microscopic analysis for aggregate}

Microscopic analysis of the lightweight aggregate are carried out by using Scanning Electron Microscope (SEM) TM3000 Table Top Microscope in order to obtain the images of the LBA before and after it was mixed in the concrete mixture. The morphology of LBA will also important to avoid segregation in concrete.

\subsection{Production of foamed concrete}

Foamed concrete also known as lightweight concrete is a concrete made up of mortars (cement, sand and water) and also foam. The proportion of the mortars were calculated by using foam excel calculation. Firstly, there are three parameters needed to be set. The three parameters are the water/cement $(\mathrm{W} / \mathrm{C})$ ratio, sand/cement $(\mathrm{S} / \mathrm{C})$ ratio and target density. $\mathrm{W} / \mathrm{C}$ ratio, $\mathrm{S} / \mathrm{C}$ ratioand target density was set to be $0.5,1$ and $1500 \mathrm{~kg} / \mathrm{m}^{3}$. After these threeparameters are set, the rest of other raw materials were calculated and came out with 9 $\mathrm{kg}$ of cement, $9 \mathrm{~kg}$ of sand and $4.5 \mathrm{~kg}$ of water and $4.23 \mathrm{~kg}$ of foam are needed in producing normal foamed concrete. The proportion of foam was taken from the proportion of production of foam in bubble aggregate which is 1:2.5 which one portion of foaming agent diluted with 2.5 portion of water.

Firstly, the foam is produced when the $1.19 \mathrm{~kg}$ of foaming agent and $2.99 \mathrm{~kg}$ of water let into the foam generator and $4.23 \mathrm{~kg}$ of foam produced is poured in the cylinder bowl. Then, the $4.23 \mathrm{~kg}$ of foam is mixed with $9 \mathrm{~kg}$ ordinary portland cement, $9 \mathrm{~kg}$ of sand and $4.50 \mathrm{~kg}$ of water in the wheelbarrow in order to cast 15 cubes of control sample. Next for the $25 \%$ substitution of lightweight bubble aggregate (LBA), it takes $4.23 \mathrm{~kg}$ of foam mix with $9 \mathrm{~kg}$ of OPC, $6.75 \mathrm{~kg}$ of sand, $2.25 \mathrm{~kg}$ of LBA and $4.50 \mathrm{~kg}$ of water in order to cast 15 cubes. Next for the third sample which is the $50 \%$ substitution of LBA, $4.230 \mathrm{~kg}$ of foam is mixed with $9 \mathrm{~kg}$ of OPC, $4.50 \mathrm{~kg}$ of sand, $4.50 \mathrm{~kg}$ of LBA and $4.50 \mathrm{~kg}$ of water. All the batches are mixed manually by hand in wheelbarrow until it is well mix as shown in Figure 3.5. The batch of each type of samples is poured into 15 cubes of $100 \mathrm{~mm} \times 100 \mathrm{~mm} \times 100$ $\mathrm{mm}$ cube without using vibrator to avoid losing of bubble particle. Then after 24 hours, remold it and placed it in the curing tank. 


\section{Results and discussion}

\subsection{Density}

In this study loose bulk density test is conducted. After conducting the test, it is found that the value of loose bulk density is $812.5 \mathrm{~kg} / \mathrm{m}^{3}$; the value is below the maximum value which is $880 \mathrm{~kg} / \mathrm{m}^{3}$ permitted in [8]. The lightweight aggregate is light due to the cellular or high internal porous microstructure, which gives this type of aggregate a low density. The lightweight aggregate is lighter due to the presence of air voids, which gives this type of aggregate a low density [9].

\subsection{Water absorption}

Water absorption of the LBA is $9.7 \%$. Since the LBA have porous structure, the lightweight aggregates absorb more water than normal aggregate.After undergoing the test for 24 hours which is according to procedure in ASTM Test Method Specific Gravity and Absorption of Coarse Aggregate ( $\mathrm{C}$ 127), lightweight aggregates will absorb from 5\% to more than $25 \%$ by weight of dry aggregate while for normal aggregates, it generally absorbs less than $2 \%$ [10].

\subsection{Aggregate impact value}

Based on the test, the value obtained is $18.99 \%$ which falls into group of strong aggregate. Table1 shows the aggregate impact value classification.

Table 1. Aggregate Impact Value Classification [11].

\begin{tabular}{|c|c|}
\hline value & group \\
\hline$<10 \%$ & Exceptionally Strong \\
\hline $10-20 \%$ & Strong \\
\hline $20-30 \%$ & Satisfactory for road surfacing \\
\hline$>35 \%$ & Weak for road surfacing \\
\hline
\end{tabular}

According to the result, the value obtained is $18.99 \%$ which is classified as strong aggregate because during the formation of LBA, the uniform paste is compressed before it is formed into a spherical shape. Due to compressed, some of the pore will diminish or the some of it will become smaller resulting increasing in strength of LBA which make it difficult to be crushed.

\subsection{Microscopic analysis for aggregate}

Based on Figure 3, pores in the LBA have a variety of shape and size. Although, the spherical shape of pores is dominating, they are also accompanied with small amount of irregular shaped pores in the aggregate. The pores are formed during the production of the aggregate as the bubbles from the foam entrapped between the cement. At the same time, sightings of cracks or fractures also can be seen which occurs resulting from the impact of a hammer as this analysis requires only a fragment of the aggregate to be enlarged using SEM. 


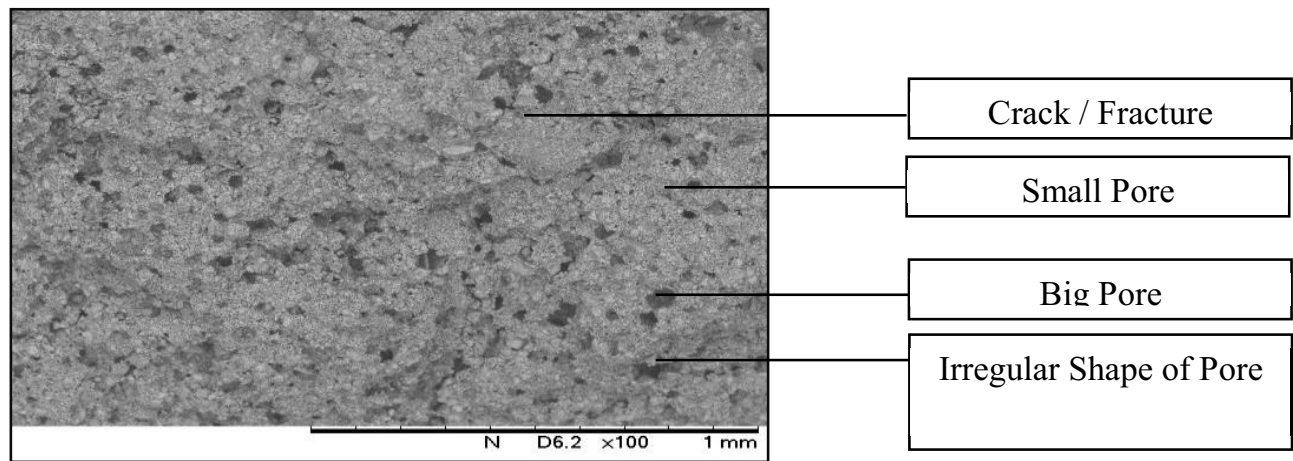

Fig. 3. Microstructure of LBA.

Figure 3 also shows that the pore in the LBA is not consistent in size. From the figure, there were many pore with different of sizes. This occurs during the production process of LBA, aluminum are not added into the mixture. Aluminum acts as a foaming agent which can create a consistent pore size [12].

\subsection{Compressive atrength of LBA foamed concrete}

Figure 4 shows the result of the samples where three type of concrete sample were used in this analysis which is the control sample, substitution $25 \%$ and $50 \%$ of LBA. All the samples were tested at the age of 7,14 and 28 days by taking an average of 3 cubes for each sample. For control sample, the foamed concrete is formed without the addition of LBA. The pattern of compressive strength is increase from day 7 to until day 28 as shown in the Figure 4. On day seven, the control samples have the strength of $2.51 \mathrm{MPa}$ and rose up to $2.80 \mathrm{MPa}$ on day 14 which it is $11.55 \%$ increase. On day 28 it show the strength of $3.21 \mathrm{MPa}$ which increases $14.6 \%$ from day 14 .

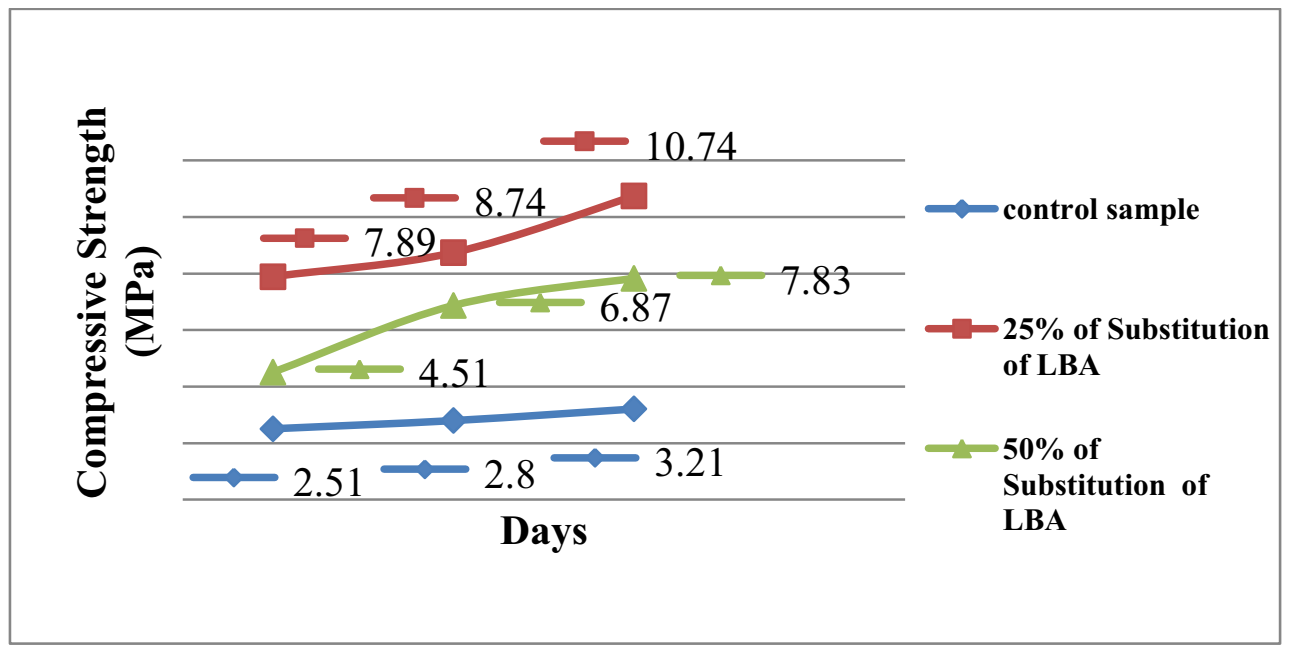

Fig. 4. Compressive Strength of LBA Foamed Concrete.

For sample with $25 \%$ substitution of LBA, the pattern of compressive strength increased with day as shown in the Figure 4.6. On day 7, the samples have the strength of $7.89 \mathrm{MPa}$ which increase up to $10.77 \%$ and on 14 th day reach the compressive strength of $8.74 \mathrm{MPa}$. 
During the final day of 28 days, the compressive strength increased up to $10.74 \mathrm{MPa}$ which rose up with $22.8 \%$ from day 14 until day 28 .

The pattern for compressive strength of $50 \%$ substitution of LBA also increases with days as in Figure 4.7 which is similar to pattern of control sample and $25 \%$ substitution of LBA. The compressive strength for 7 days is $4.51 \mathrm{MPa}$ and increase up to $6.87 \mathrm{MPa}$. The increase of percentage from day 7 to day 14 is $52.3 \%$ which is higher compare to control sample and sample of 25 substitution of LBA for period of 8 days. During final day which is day 28 , the compressive strength of the sample rose up to 7.83 from day 14 which increased $13.97 \%$.

\section{Conclusions}

The strength of foamed concrete with $25 \%$ substitution of of LBA is higher compare to $50 \%$ substitution of LBA and control sample with $10.738 \mathrm{MPa}$ but past research has confirmed that strength of foamed concrete can achieve up to $15 \mathrm{MPa}$. In this study, the $25 \%$ substitution of LBA is the optimum percentage required in order to enhance the strength of foamed concrete. For density, the density of foamed concrete is increasing as the LBA is increasing. The results show that $50 \%$ substitution of LBA has density of 1832 $\mathrm{kg} / \mathrm{m}^{3}$ which is the highest, followed by $25 \%$ substitution of LBA with $1735 \mathrm{~kg} / \mathrm{m}^{3}$ and normal lightweight concrete with $1577 \mathrm{~kg} / \mathrm{m}^{3}$ All the value for the density is in the range of foamed concrete density which is below than maximum value, $1840 \mathrm{~kg} / \mathrm{m}^{3}$.

\section{References}

1. O. Kayali, World of Coal Ash Conference, Lexington, Kentucky, USA (2005)

2. P. Shafigh, M.Z. Jumaat, H. Mahmud, H, Constr. Build. Mater., 25(4), 1848 (2011)

3. K. Ramamurthy, E.K.K. Nambiar, G.I.S Ranjani, Cement Concrete Comp, 31(6), 388 (2009)

4. Nadia Salim, T.M. Dhirar, Al-Taqani, 25, 160 (2012)

5. L.Q. Wen, Properties Of Concrete Made From Lightweight Aggregate Under Different Curing Time, Universiti Malaysia Perlis (2014)

6. American Standard, Standard Test Method for Bulk Density ("Unit Weight”) and Voids in Aggregate (ASTM C29/C29M, 2009)

7. American Standard, Standard Test Method for Density, Relative Density (Specific Gravity), and Absorption of Coarse Aggregate (ASTM 127, 2012)

8. American Standard, Standard Specification for Lightweight Aggregates for Stuctural Concrete (ASTM C330, 1999)

9. F. Zulkarnain, M. Ramli, $2^{\text {nd }}$ International Conference on Built Environment in Developing Countries, Penang, Malaysia (2009)

10. American Concrete Institute, Guide for Structural Lightweight-Aggregate Concrete (ACI 213R, 2003)

11. http://civilblog.org/about/

12. B. Middendorf, Mater. Charact., 60(7), 741 (2009) 